\title{
Surgical Management of Frenula: Laser Therapy Compared with Z-Frenuloplasty Technique
}

\author{
Paola Martina Marra ${ }^{1}$ (D), Angelo Itro ${ }^{1}$ (D)
}

${ }^{1}$ Complex Operative Unit of Stomatological Surgery in Developmental Age, University of Campania Luigi Vanvitelli, Naples, Italy.

Author to whom correspondence should be addressed: Paola Martina Marra, Complex Operative Unit of Stomatological Surgery in Developmental Age, University of Campania Luigi Vanvitelli, Naples, Italy. Phone: +39 3338626207 . E-mail: pablati3@hotmail.it.

Academic Editor: Alessandro Leite Cavalcanti

Received: 21 February 2020 / Accepted: 06 April 2020 / Published: 03 July 2020

How to cite this article: Marra PM, Itro A. Surgical management of frenula: laser therapy compared with Z-frenuloplasty technique. Pesqui Bras Odontopediatria Clín Integr. 2020; 20:e0027. https://doi.org/10.1590/pboci.2020.124

\begin{abstract}
Objective: To compare intra- and post-operative consequences associated with Z-frenuloplasty and laser therapy for both upper labial and lingual frenulectomies. Material and Methods: Clinical data of 120 consecutive patients with a mean age of 11 years and 2 months (age range from 9 years and 1 month to 14 years and 3 months) with hypertrophic labial and lingual frenula were assembled. Of the 70 labial frenula, 35 were removed through Z-frenuloplasty (Group 1) and 35 with laser (Group 2); of 50 lingual frenula, instead, 25 were extracted through Z-frenuloplasty (Group 1A) and 25 with laser (Group 2A). The cutting device was Laser Diode Handy 10 in continuous mode. Finally, the time of the surgery, pain and swelling were measured 24-48 hours after the removal. VAS scale was used. Results: The time of the surgery, VAS score after the removal and the swelling were lesser in Group 2 and $2 \mathrm{~A}$. Conclusion: Both Z-frenuloplasty and Laser therapy are valid instruments to remove frenula. Moreover, laser offers more advantages like less use of anesthesia, no bleeding in the operating phase, no need for suturing, a faster tissue healing and minor limitations in speech and nutrition.
\end{abstract}

Keywords: Children; Lingual Frenum; Labial Frenum; Surgery, Oral; Minor Surgical Procedures. 


\section{Introduction}

Frenulectomy may be required for abnormal hypertrophic frenula. Several surgical techniques have been proposed [1-3], like simple clipping with blades in newborns (also known as frenotomy), Z-frenuloplasty, cryosurgery, electrocauterisation and lasers (Light Amplification by Stimulated Emission of Radiation).

Specifically, as regards lasers, according to some authors [4,5], throughout a penetrating beam of light, these appliances deliver a quantity of energy at InfraRed and UltraViolet electromagnetic spectra ranges that can be used in most oral surgeries as an alternative to conventional scalpel-based techniques. Usually, after a surgery, sutures are no needed, there is a rapid tissue healing and there is no bleeding in the operating phase.

Regarding, instead, the traditional surgical methods, Z-frenuloplasty is based on the incisions that are made to turn up flaps, which are later repositioned in a 'Z-plasty' flap closure [6]. In the case of maxillary diastema, for example, the premaxilla scar tissue is excised, and the site is left to granulate and heal; usually, sutures are removed a week later. Unlike the laser protocol, habitually, after surgery, since there is bleeding during the operating phase, sutures are needed.

The maxillary labial frenulum is a small, somewhat triangular fold of nonmuscular fibrous connective tissue extending from the midline maxillary gingiva into the vestibule and central upper lip that originates as a posteruptive remnant of embryonic tectolabial bands [6-9].

It can affect facial esthetics and oral function by retracting the gingival margin, creating a median diastema, and limiting lip movement. It can also result in periodontal and speech problems [6]. Regarding lingual frenula, it can be defined as a fibrous attachment under the tongue, which stabilizes its movement [10]; so, its incorrect position can have some implications for the stomatognathic system causing, for example, difficulties in speech, sucking/swallowing, feeding problems in infants (particularly in newborns) and young children, articulation problems [10-13].

The aim of this study was to compare intra- and post-operative consequences associated with Zfrenuloplasty and Laser therapy for both upper labial and lingual frenulectomies. Moreover, pain and swelling were investigated 24 and 48 hours after surgery.

\section{Material and Methods}

Study Design and Sample

This study was conducted at Complex Operative Unit of Stomatological Surgery in Developmental Age of University of Campania Luigi Vanvitelli, Naples, Italy. The sample group was composed of 120 consecutive patients with a mean age of 11 years and 2 months (age range from 9 years and 1 month to 14 years and 3 months) with hypertrophic labial and lingual frenula. All of them came to the Hospital as a first visit.

\section{Clinical Procedures}

Of the 70 upper labial frenula, 35 were removed through Z-frenuloplasty (Group 1) and 35 with Laser Diode (Group 2); of 50 lingual frenula, instead, 25 were extracted through Z-frenuloplasty (Group 1A) and 25 with Laser Diode (Group 2A).

The cutting device utilized was the Laser Handy 10 with wavelength $=810-980 \mathrm{~nm}$; fibre $=320-400$ $\mu \mathrm{m}$; power $=1.8-3 \mathrm{~W}$, and energy dose $=272$ joules, in continuous mode. The surgery's time, the pain (using a VAS scale) and swelling 24 and 48 hours after surgery were evaluated. No cases of patients with hypertrophic 
labial lower frenula were found. The exclusion criteria were patients with epilepsy, benign tumors with malignant tendency, general health problems and patients treated with substances sensible to light.

The same surgeon with a long-time training and experience carried out all frenulectomies using local anaesthesia (2\% lidocaine with 1:100.000 epinephrine) in patients treated with Z-frenuloplasty and topical anaesthesia in patients treated with Laser therapy.

After frenulectomies, post-operative instructions were given. Patients were asked to provide a soft diet for a week, take analgesics if needed and maintain good oral hygiene. No antibiotics were prescribed.

\section{Results}

In the four groups, the time of the surgery, pain and swelling 24 and 48 hours after the removal were evaluated. As regards the meantime of surgery, in groups ( 1 and $1 \mathrm{~A})$, it was 15 minutes, while in groups (2 and 2A) was 7 minutes. Concerning, instead, the post-operative time, pain and swelling were greater in groups (1 and $1 \mathrm{~A})$.

As regards the pain, the patients were asked to mark on the scale from 1 to 10 centimeters the exact point as they perceived the pain in order to attribute a value to the subjective disturbance. Twenty-four hours after surgery, the mean of subjective pain showed by patients in groups ( 1 and 1A) was 5 , while in groups (2 and $2 \mathrm{~A}$ ) was 2 . Fourty-eight hours after surgery, the mean of subjective pain in groups (1 and $1 \mathrm{~A}$ ) was 2 , while in groups ( 2 and $2 \mathrm{~A})$ was 0.

Regarding the swelling, all patients were visited 24 and 48 hours after surgery to check the entity of the swelling; in Group 1, it was present 24 hours after surgery, decreasing 48 hours after; in Group 1A, no signs of swelling were observed. In both Groups 2 and $2 \mathrm{~A}$ no signs of swelling were observed.

\section{Discussion}

The labial frenulum is a small fold of tissue that supports or checks the motion of the part to which it is attached, in particular a fold of skin beneath the tongue, or between the lip and the gum. It is made of connective tissue and elastic and collagen fibers; muscular fibers originating from the orbicularis and fat tissue can be also present [12-15].

An abnormal frenulum on thin gingival biotype can induce, through ischemic phenomena resulting from traction, a buccal recession of the gingival margin. It can also interfere with adequate oral hygiene causing marginal gingivitis in the surrounding areas [14,15].

The lingual frenula, instead, is a small fold of mucous membrane extending from the floor of the mouth to the midline of the underside of the tongue. Its abnormal length can cause difficulties in sucking, swallowing and speech. The oral dysfunction induced by a short lingual frenulum can lead to oral-facial dysmorphosis, which also decreases the size of upper airway support. A short lingual frenulum left untreated at birth can be associated with OSAS at a later age [13-17].

Normally at birth, the tongue is placed high in the palate, and its continuous activity related to sucking, swallowing and masticating induces stimulation of the intermaxillary synchondrosis [3,13], which is active until 13-15 years of age, leading to normal oral-facial growth. Normal nasal breathing is associated with this tongue position.

The literature agrees with the concept that in older children, speech difficulties have been associated to an untreated short frenulum [18,19]; moreover, it was also shown that mouth breathing with modification of the position of the tongue and secondary orthodontic impacts, caused an anterior and posterior crossbite, an 
unbalanced growth of the mandible and irregular growth of the maxilla [20,21]. So, it was very important to treat all patients that came to the hospital after our diagnosis of hypertrophic labial and lingual frenula to correct or prevent this kind of problem.

In these patients, the perception of pain (VAS score at 2 and 0,24 and 48 hours after the removal), following frenulectomy was lesser when Laser Diode surgery was utilized, compared with Z-frenuloplasty technique. These results derive from beam delivery system possessed by diode Lasers that employ an optical flexible fiber handpiece, a semiconductor associated with aluminium and gallium highly absorbed by haemoglobin but poorly absorbed by water [14-17].

Therefore, in addition to these advantages, Laser devices provide bloodless surgical field, absence of sutures, minimal swelling and post-surgical pain; specifically, as regards the lingual frenulum, the literature reports that the manipulation and suturing of the lingual ventral surface after scalpel frenulectomy may occasionally cause obstruction of Warton's duct, damage to lingual nerve branches or sublingual blood vessels, and numbness of the tongue tip [22,23].

The risk of local infection is also reduced due to Laser capability of sterilization of the surgical site, which avoids the use of antibiotic therapy [16,17]. Laser therapy is usually used both in adulthood and in childhood resulting in very useful in any surgical procedures.

According to the literature, Z-Frenuloplasty technique showed a statistically significant improvement of frenulum length and tongue protrusion compared to the other methods [24-26]. Furthermore, it was also found that $91 \%$ of the patients who underwent the Z-frenuloplasty showed an improvement in speech [24]. In the current study, though this technique, the flap's repositioning is carried out with less soft tissue tension and minimal scarring.

Compared with surgery with scalpels, Laser procedures are superior regarding post-operative pain and discomfort and functional complications, according to the patients' perceptions. All the patients were seen a week later for a check and nobody reported any complications (pain, intra/extra oral swelling, infection, bad taste, and redness).

\section{Conclusion}

Early diagnosis and treatment of hypertrophic labial and lingual frenula are necessary for the adequate functional oral development of young patients. Specifically, as regards the lingual frenula, its timely treatment avoids sucking and swallowing difficulties, the establishment of malocclusions and bad oral habits since the incorrect position of the tongue with early in life. Both Z-frenuloplasty and Laser Diode therapy are valid instruments to remove frenula. Moreover, Lasers provide a more efficient and comfortable treatment and offers more advantages compared to traditional scalpel/blade methods: less use of anesthesia, no bleeding in the operating phase, no need for suturing at the end of the operation, rapid tissue healing and no limitation in speech and nutrition. For this reason, the Laser is a quick, practical and painless operation.

\section{Authors' Contributions}

PMM (D) 0000-0001-9863-8966 Investigation, Writing - Original Draft Preparation, Writing - Review and Editing.

AI (D) 0000-0003-0297-272X Conceptualization, Methodology and Writing - Review and Editing. All authors declare that they contributed to critical review of intellectual content and approval of the final version to be published. 


\section{Financial Support}

None.

\section{Conflict of Interest}

The authors declare no conflicts of interest.

\section{References}

[1] Tuli A, Singh A. Monopolar diathermy used for correction of ankyloglossia. J Indian Soc Pedod Prev Dent 2010; 28(2):130-3. https://doi.org/10.4103/0970-4388.66757

[2] Lamba AK, Aggarwal K, Faraz F, Tandon S, Chawla K. Er, Cr:YSGG laser for the treatment of ankyloglossia. Indian J Dent 2015; 6(3):149-52. https://doi.org/10.4103/0975-962X.163049

[3] Tsaousoglou P, Topouzelis N, Vouros I, Sculean A. Diagnosis and treatment of ankyloglossia: a narrative review and a report of three cases. Quintessence Int 2016; 47(6):523-34. https://doi.org/10.3290/j.qi.a36027

[4] Seifi M, Matini NS. Laser surgery of soft tissue in orthodontics: review of the clinical trials. J Lasers Med Sci 2017; 8(Suppl 1):S1-S6. https://doi.org/10.15171/jlms.2017.s1

[5] Nicoloso GF, Santos IS, Flores JA, Silveira BL, Machado MDM. An alternative method to treat ankyloglossia. J Clin Pediatr Dent 2016; 40(4):319-2 1. https://doi.org/10.17796/1053-4628-40.4.319

[6] Dusara K, Mohammed A, Nasser NA. Z-frenuloplasty: A better way to 'untangle' lip and tongue ties. J Dent Oral Disord Ther 2014; 2(1):1-4. https://doi.org/10.15226/jdodt.2014.00109

[7] Henry SW, Levin MP, Tsaknis PJ. Histologic features of the superior labial frenum. J Periodontol 1976; 47(1):25-8. https://doi.org/10.1902/jop.1976.47.1.25

[8] Edwards JG. The diastema, the frenum, the frenectomy: a clinical study. Am J Orthod 1977; 71(5):489-508. https://doi.org/10.1016/0002-9416(77)90001-x

[9] Kotlow LA. The influence of the maxillary frenum on the development and pattern of dental caries on anterior teeth in breastfeeding infants: prevention, diagnosis, and treatment. J Hum Lact 2010; 26(3):304-8. https://doi.org/10.1177/0890334410362520

[10] Huang WJ, Creath CJ. The midline diastema: a review of its etiology and treatment. Pediatr Dent 1995; 17(3):171-9.

[11] Boutsi EA, Tatakis DN. Maxillary labial frenum attachment in children. Int J Paediatr Dent 2011; 21(4):284-8. https://doi.org/10.1111/j.1365-263X.2011.01121.x

[12] Ceremello PJ. The superior labial frenum and the midline diastema and their relation to growth and development of the oral structures. Am J Orthod 1953; 39(2):120-39. https://doi.org/10.1016/0002-9416(53)90016-5

[13] Ghaheri BA, Cole M, Fausel SC, Chuop M, Mace JC. Breastfeeding improvement following tongue-tie and lip-tie release: A prospective cohort study. Laryngoscope 2017; 127(5):1217-23. https://doi.org/10.1002/lary.26306

[14] Ambika S, Suchithra MS. Diode laser in pediatric dentistry. Int J Sci Res 2018; 7(2):363-9.

[15] Aldelaimi TN, Mahmood AS. Laser-assisted frenectomy using 980nm diode laser. J Dent Oral Dis Ther 2014; 2(4):16. https://doi.org/10.15226/jdodt.2014.00130

[16] Aras MH, Göregen M, Güngörmüş M, Akgül HM. Comparison of diode laser and Er:YAG lasers in the treatment of ankyloglossia. Photomed Laser Surg 2010; 28:173-7. https://doi.org/10.1089/pho.2009.2498

[17] Asnaashari M, Zadsirjan S. Application of laser in oral surgery. J Lasers Med Sci 2014; 5(3):97-107.

[18] García Pola MJ, García MG, Martín JMG, Gallas M, Lestón JS. A study of pathology associated with short lingual frenum. ASDC J Dent Child 2002; 69(1):59-62.

[19] Lalakea ML, Messner AH. Ankyloglossia: the adolescent and adult perspective. Otolaryngol Head Neck Surg 2003; 128(5):746-52

[20] Tanay V. Chaubal, Mala Baburaj Dixit Ankyloglossia and its management. J Indian Soc Periodontol 2011; 15(3):2702. https://doi.org/10.4103/0972-124X.85673

[21] Marchesan IQ. Lingual frenulum: classification and speech interference. Int J Orofacial Myology 2004; 30:3 1-8.

[22] Butchi Babu K, Kiran Uppada U, Koppolu P, Mishra A, Chandra CR, Pandey R. Management of ankyloglossia: have lasers taken the sheen away from scalpel. J Dent Lasers 2014; 8(2):56-9.

[23] Crippa R, Paglia M, Ferrante F, Ottonello A, Angiero F. Tongue-ties assessment: clinical aspects and a new diode laser techinque for its management. Eur J Paediatr Dent 2016; 17(3):220-2.

[24] Heller J, Gabbay J, O'Hara C, Heller M, Bradley JP. Improved ankyloglossia correction with four-flap Zfrenuloplasty. Ann Plast Surg 2005; 54(6):623-8. https://doi.org/10.1097/01.sap.0000157917.91853.be

[25] Puig JR, Lefebvre E, Landat F. Z-plasty technic, applied to hypertrophy of the upper labial frenum. Rev Stomatol Chir Maxillofac 1977; 78(5):351-6.

[26] Chinnadurai S, Francis DO, Epstein RA, Morad A, Kohanim S, McPheeters M. Treatment of ankyloglossia for reasons other than breastfeeding: a systematic review. Pediatrics 2015; 135(6):e1467-74. https://doi.org/10.1542/peds.2015-0660 